\section{RMD Open}

Rheumatic \&

Musculoskeletal Diseases

To cite: Manara M, Sinigaglia L. Bone and TNF in rheumatoid arthritis: clinical implications. RMD Open 2015;1:e000065.

doi:10.1136/rmdopen-2015000065

- Prepublication history for this paper is available online. To view these files please visit the journal online (http://dx.doi.org/10.1136/ rmdopen-2015-000065)

Received 10 February 2015 Accepted 13 July 2015

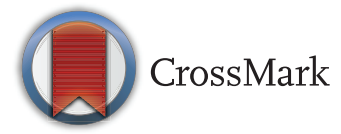

Department of

Rheumatology, Gaetano Pini Institute, Milan, Italy

Correspondence to Dr Maria Manara; maria.manara@gmail.com

\title{
Bone and TNF in rheumatoid arthritis: clinical implications
}

\author{
Maria Manara, Luigi Sinigaglia
}

\section{ABSTRACT}

Experimental data have demonstrated that tumour necrosis factor (TNF) plays a significant role in systemic and local bone loss related to rheumatoid arthritis (RA). In clinical studies on patients with RA, treatment with TNF inhibitors was able to arrest systemic bone loss assessed by bone mineral density and bone turnover markers, but there is scarce evidence of a clinically meaningful effect of TNF inhibition in preventing fractures. TNF inhibitors showed a higher efficacy in reducing radiographic progression related to the disease compared to methotrexate in randomised clinical trials. Data from observational studies seem to confirm the effectiveness of anti-TNF therapy in reducing joint damage evolution.

\section{TUMOUR NECROSIS FACTOR AND BONE IN RHEUMATOID ARTHRITIS}

The impact of rheumatoid arthritis (RA) on bone metabolism is well established both in terms of enhanced systemic bone loss, that is, osteoporosis and increased fracture risk, and local bone loss, that is, periarticular bone loss and erosions, leading to joint damage.

Systemic inflammation and some other disease-related factors, such as reduced mobility and treatments like corticosteroids, have been implicated in the pathogenesis of systemic bone loss together with other generic risk factors for osteoporosis like, for example, advanced age and female sex. In recent years, the specific role of inflammatory mediators involved in the pathogenesis of RA in this context has been better clarified, and it has been demonstrated that these molecules act interactively on bone cells.

Tumour necrosis factor (TNF) is considered one of the main mediators of joint inflammation in RA. A number of experimental studies have demonstrated that it plays a significant role in local joint damage and systemic bone loss, as it increases osteoclast (OC) mediated bone resorption. TNF enhances OC activity by directly promoting

\section{Key messages}

What is already known about this subject?

- Tumour necrosis factor (TNF) can induce bone loss in rheumatoid arthritis. Treatment with TNF inhibitors may exert a protective effect on systemic and local bone loss related to the disease.

What does this study add?

- This review summarises the results of published studies assessing the effect of treatment with TNF inhibitors on systemic and local bone loss in rheumatoid arthritis. Overall, published data support the efficacy of anti-TNF therapy in reducing radiographic progression, but data on fracture prevention are scarce.

How might this impact on clinical practice?

- Since evidences on the effect of anti-TNF treatment in preventing fractures are still scarce, clinicians should be made aware of the need for a proper treatment of systemic bone loss in patients with rheumatoid arthritis.

OC differentiation of bone marrow macrophages exposed to permissive levels of RANK-ligand (RANKL), ${ }^{1}$ by stimulating RANKL expression by T and B lymphocytes, ${ }^{2}$ by promoting stromal RANKL production by osteoblasts (OB), and by enhancing RANK and IL-1 expression by myeloid OC precursors. ${ }^{3}$ TNF's inhibitory effect on OB proliferation has also been documented. ${ }^{4}$ Furthermore, it has been shown that TNF plays a role in the regulation of the Wnt signalling pathway: TNF can induce the Wnt inhibitor dickkopf-1 (Dkk-1), thus suppressing systemic bone formation and local bone repair mediated by the Wnt pathway. ${ }^{5}$ More recently, anticitrullinated protein antibodies have been demonstrated to stimulate the release of TNF after binding to OC precursors, inducing OC differentiation and activation. ${ }^{6}$ On this basis, it was hypothesised that anti-TNF treatment could potentially have an effect on systemic bone loss not only due to a generic anti-inflammatory action, but also to a specific inhibition of TNF. 


\section{TNF IN THE PATHOPHYSIOLOGY OF EROSION AND JOINT NARROWING}

Bone erosion represents the most distinctive radiographic sign of joint damage in RA and it has not only diagnostic, but also prognostic value, since it is utilised as one of the main outcome measures in clinical trials. The development of bone erosions is strictly related to local joint inflammation and often preceded by periarticular osteoporosis on radiographs. The introduction of MRI in clinical practice allowed for identification of an altered signal in the subchondral bone adjacent to the joint areas, corresponding to a bone marrow infiltrate of inflammatory cells on histology examination. ${ }^{7}$ These lesions have been demonstrated to predict subsequent erosions. ${ }^{8}$ Therefore, in addition to the classical view of an inflamed synovial tissue penetration of bone from 'outside', a role of bone marrow inflammation has also been hypothesised in the pathogenesis of erosions. ${ }^{9}$

Clinical studies showing an association between systemic osteoporosis and erosion development may suggest a common pathogenic mechanism for systemic and local bone loss. ${ }^{10} 11$ Since the identification of OC in the synovial inflammatory tissue of patients with RA, ${ }^{12}$ the idea that these cells may play a fundamental role in the pathogenesis of joint damage has been postulated. TNF produced by the inflamed synovium can induce OC-mediated bone damage in the joint by directly triggering OC differentiation or promoting it indirectly by stimulating RANKL expression on synovial fibroblast and $\mathrm{T}$ cell. ${ }^{13-15}$ Experimental data on mice with induced arthritis showed that erosive damage is strictly related to OC activity, since RANKL knockout mice developed only joint inflammation but no erosions. ${ }^{16}$ A local inhibition of bone formation mediated by TNF-induced production of DKK-1 by synovial fibroblasts could also account for a defective repair of bone erosions in patients with RA (figure 1). ${ }^{5}$

\section{TNF INHIBITION AND SYSTEMIC BONE LOSS}

A number of clinical studies were conducted to assess the effect of treatment with TNF inhibitors on bone mineral density (BMD) in patients with RA (table 1). ${ }^{17-30}$

Almost all studies demonstrated that treatment with anti-TNF could arrest the decrease of BMD related to the disease and sometimes even increase BMD values. Conflicting findings emerged from studies in which the effect on BMD was compared between clinical responders and non-responders to the treatment: in a cohort study on patients treated with infliximab and methotrexate (MTX), a positive effect on BMD was found only in clinical responders, ${ }^{17}$ while in another study with a historical group of controls a beneficial effect on BMD values was also found in clinical non-responders. ${ }^{19}$ These data raise the question of whether the effect of anti-TNF treatment on BMD is due only to clinical inflammation suppression or is also related to a specific TNF inhibition. The findings of the BeSt study of similar BMD variations among patients treated with infliximab and other non-biological disease-modifying antirheumatic drugs (DMARDs) combinations ${ }^{21}$ suggest that the beneficial effect of anti-TNF treatment could be mainly related to systemic inflammation suppression. Moreover, previous studies showed that, in patients treated with low dosages of glucocorticoids, the negative effect of these drugs on bone metabolism is somehow counteracted by the benefits derived from the suppression of inflammation: this observation further supports the hypothesis that the beneficial effect of the treatment of RA on bone could mainly be related to the control of inflammation. $^{31} 32$

Other studies focused on the effect of TNF inhibition on bone turnover markers: an overall positive effect on bone turnover markers was observed, with an increase in bone formation and a decrease in bone resorption markers (table 2). ${ }^{17-20} 22$ 28-30 33-38

Serum levels of RANKL and the RANKL/OPG ratio were tested in different cohorts and an overall reduction of these markers of OC activity was found in patients treated with TNF inhibitors. ${ }^{17}{ }^{34}$ More recently, a relative reduction of serum levels of DKK1 was documented after treatment with anti-TNF. ${ }^{39}$

Despite the existence of a large amount of data on surrogate end points of bone fragility, data on fractures in patients treated with anti-TNF are scarce. In a recent study on 9020 patients with RA identified from administrative databases, the risk of fractures did not differ between patients treated with TNF inhibitors or other DMARDs, and only a concomitant treatment with $>10 \mathrm{mg}$ /day of prednisone equivalent was a significant predictor of fracture. ${ }^{40}$ In another population-based cohort study, the risk of non-vertebral osteoporotic fractures was not different between subjects treated with TNF inhibitors or other DMARDs. ${ }^{41}$ These findings are in line with data from a large population-based study in Canada, which showed no reduction in fracture rates among patients with RA between 2003 and 2008. ${ }^{42}$

\section{TNF INHIBITION AND LOCAL BONE LOSS}

In addition to the effects of TNF inhibition on systemic bone loss, a few studies have evaluated the influence of the treatment on local bone loss measured by metacarpal BMD (table 1). $.^{17} 23252743-45$ Most of them found that the stabilisation of spine or hip BMD values after treatment with TNF inhibitors was not accompanied by a similar effect on hand BMD. However, the real significance of local BMD measurement still needs to be defined.

The main manifestation of local bone damage in RA is the development of erosions and joint destruction, which can be measured in terms of radiographic progression by different scoring methods on X-rays. This issue was investigated in most of the controlled trials performed to assess the efficacy of TNF inhibitor therapy, since the prevention of joint damage is one of the primary goals of the treatment. Therefore, a great deal 

bone metabolism in rheumatoid arthritis. (A) TNF directly promotes osteoclast RANKL production by osteoblasts, fibroblasts and $\mathrm{T}$ cells, thus enhancing osteoclast DKK-1 production by synovial fibroblasts, thus inhibiting osteoblast proliferation. DKK-1, Dickkopf WNT Signaling Pathway Inhibitor 1; RANKL, receptor activator of the NFkappaB ligand; TNF, tumour necrosis factor.
Figure 1 Effects of TNF on differentiation; (B) TNF stimulates proliferation; (C) TNF stimulates

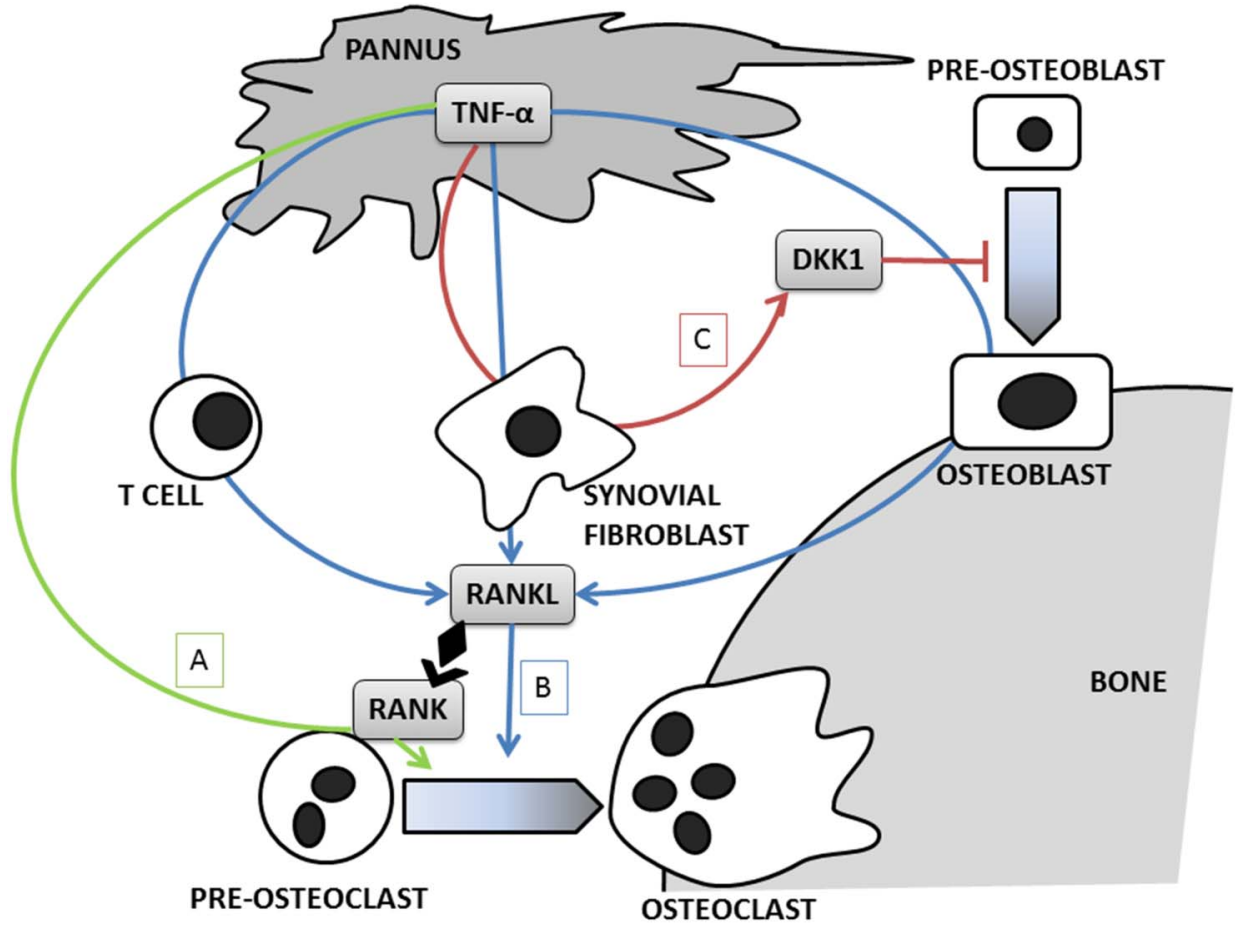

of data is available on the higher efficacy of anti-TNF treatment compared to conventional DMARDs (namely MTX) in reducing radiographic damage progression. ${ }^{46-53}$ In a meta-analysis of trials that assessed the efficacy of different biological therapies in terms of radiographic damage prevention, the treatment with biological drugs was shown to be more efficacious than MTX alone both in patients in early stages of the disease and in those with long-standing RA; however, owing to a high heterogeneity of study populations, an indirect comparison between different biologics was not feasible. ${ }^{54}$

Table 1 Main results of studies assessing the effect of anti-TNF treatment on bone mineral density in patients with rheumatoid arthritis

\begin{tabular}{|c|c|c|c|c|c|c|c|c|c|c|c|}
\hline \multirow[b]{2}{*}{ Author } & \multirow[b]{2}{*}{ Year } & \multirow[b]{2}{*}{ Drug } & \multirow{2}{*}{$\begin{array}{l}\text { Patients } \\
\text { (n) }\end{array}$} & \multirow{2}{*}{$\begin{array}{l}\text { Controls } \\
\text { (n) }\end{array}$} & \multirow{2}{*}{$\begin{array}{l}\text { Follow-up } \\
\text { (months) }\end{array}$} & \multicolumn{2}{|c|}{ Femoral BMD } & \multicolumn{2}{|c|}{ Lumbar BMD } & \multicolumn{2}{|c|}{$\begin{array}{l}\text { Hand } \\
\text { BMD }\end{array}$} \\
\hline & & & & & & Pts & Ctr & Pts & Ctr & Pts & Ctr \\
\hline Lange & 2005 & INF & 26 & - & 12 & $\uparrow$ & - & $\uparrow$ & - & - & - \\
\hline Vis & 2005 & INF & 36 & - & 12 & $\begin{array}{l}\downarrow \\
\text { (NS) }\end{array}$ & - & $\begin{array}{l}\uparrow \\
(\mathrm{NS})\end{array}$ & - & - & - \\
\hline Seriolo & 2006 & INF/ETA & $9 / 11$ & 10 & 6 & $\begin{array}{l}\uparrow \\
\text { (NS) }\end{array}$ & $\begin{array}{l}\downarrow \\
\text { (NS) }\end{array}$ & $\begin{array}{l}\uparrow \\
\text { (NS) }\end{array}$ & $\begin{array}{l}\downarrow \\
\text { (NS) }\end{array}$ & $(\uparrow)$ & $(\downarrow)$ \\
\hline Vis & 2006 & INF & 102 & - & 12 & $\leftrightarrow$ & - & $\leftrightarrow$ & - & $\downarrow$ & - \\
\hline Marotte & 2007 & INF & 90 & 99 & 12 & $\leftrightarrow$ & $\downarrow$ & $\leftrightarrow$ & $\downarrow$ & - & - \\
\hline Chopin & 2008 & INF & 48 & - & 12 & $\leftrightarrow$ & - & $\leftrightarrow$ & - & - & - \\
\hline Guler-Yuksel & 2008 & INF & 88 & 254 & 12 & $\begin{array}{l}\downarrow \\
\text { (NS) }\end{array}$ & $\begin{array}{l}\downarrow \\
\text { (NS) }\end{array}$ & $\begin{array}{l}\downarrow \\
\text { (NS) }\end{array}$ & $\begin{array}{l}\downarrow \\
\text { (NS) }\end{array}$ & - & - \\
\hline Haugeberg & 2009 & INF & 10 & 10 & 12 & $\leftrightarrow$ & $\downarrow$ & $\downarrow$ & $\downarrow$ & $\downarrow$ & $\downarrow$ \\
\hline Hoff & 2009 & ADA & $261+261$ & 246 & 24 & - & - & - & - & $\downarrow$ & $\downarrow$ \\
\hline Wijbrandts & 2009 & ADA & 50 & - & 12 & $\leftrightarrow$ & - & $\leftrightarrow$ & - & - & - \\
\hline Eekman & 2011 & INF & 52 & - & 24 & $\leftrightarrow$ & - & $\uparrow$ & - & $\downarrow$ & - \\
\hline Hoff & 2011 & ADA & 214 & 188 & 12 & - & - & - & - & $\downarrow$ & $\downarrow$ \\
\hline Bertoldi & 2013 & ETA & 5 & 7 & 12 & - & - & - & - & $\uparrow$ & $\uparrow$ \\
\hline Dischereit & 2013 & INF & 18 & - & 24 & $\leftrightarrow$ & - & $\downarrow$ & - & - & - \\
\hline Krieckaert & 2013 & ADA & 184 & - & 48 & $\downarrow$ & - & $\leftrightarrow$ & - & $\downarrow$ & - \\
\hline Szentpetery & 2013 & ETA/ADA/INF & 35 & - & 36 & $\downarrow$ & - & $\leftrightarrow$ & - & $\leftrightarrow$ & - \\
\hline Okano & 2014 & INF/ETA & $90 / 27$ & 102 & 12 & $\leftrightarrow$ & $\downarrow$ & $\leftrightarrow$ & $\leftrightarrow$ & - & - \\
\hline
\end{tabular}


Table 2 Main results of studies assessing the effect of anti-TNF treatment on markers of bone turnover in RA

\begin{tabular}{|c|c|c|c|c|c|c|c|c|c|c|c|c|}
\hline Author & Year & Drug & Patients (n) & RANKL & OPG & RANKL/OPG & OC & PINP & CTX & NTX & DPD & BAP \\
\hline Ziolkowska & 2002 & INF & 21 & $\downarrow$ & $\downarrow$ & $\leftrightarrow$ & - & - & - & - & - & - \\
\hline Vis & 2003 & INF & 68 & - & - & - & $\uparrow$ & $\uparrow$ & - & - & - & $\leftrightarrow$ \\
\hline Lange & 2005 & INF & 26 & - & - & - & $\uparrow$ & - & - & - & - & - \\
\hline Seriolo & 2006 & INF/ETA & $9 / 11$ & - & - & - & $\uparrow$ & - & - & - & $\downarrow$ & - \\
\hline Torikai & 2006 & INF & 17 & - & - & - & - & - & - & $\downarrow$ & $\downarrow$ & $\leftrightarrow$ \\
\hline Vis & 2006 & INF & 102 & $\downarrow$ & $\leftrightarrow$ & $\downarrow$ & $\leftrightarrow$ & - & $\downarrow$ & - & - & - \\
\hline Marotte & 2007 & INF & 90 & - & - & - & $\leftrightarrow$ & - & $\leftrightarrow$ & - & - & - \\
\hline Chopin & 2008 & INF & 48 & - & - & - & - & $\leftrightarrow$ & $\leftrightarrow$ & - & - & - \\
\hline Yasunori & 2008 & ETA & 30 & $\downarrow$ & $\leftrightarrow$ & $\downarrow$ & - & - & - & - & $\downarrow$ & - \\
\hline Dischereit & 2013 & INF & 18 & - & - & - & $\uparrow$ & - & - & - & - & - \\
\hline Korczowska & 2013 & INF & 36 & - & - & - & $\downarrow$ & - & - & $\downarrow$ & $\downarrow$ & - \\
\hline Szentpetery & 2013 & INF/ETA/ADA & 35 & - & - & - & $\leftrightarrow$ & $\leftrightarrow$ & $\downarrow$ & - & $\downarrow$ & $\uparrow$ \\
\hline Lim & 2014 & ETA & 33 & - & - & $\leftrightarrow$ & - & $\leftrightarrow$ & $\uparrow$ & - & - & $\leftrightarrow$ \\
\hline Okano & 2013 & INF/ETA & $90 / 27$ & - & - & - & - & - & - & $\downarrow$ & - & $\leftrightarrow$ \\
\hline
\end{tabular}

ADA, Adalimumab; BAP, bone alkaline phosphatase; CTX, C- telopeptide of type I collagen; DPD, deoxypyridinoline; ETA, etanercept; INF, infliximab; NTX, N-telopeptide of type I collagen; OC, osteocalcin; OPG, osteoprotegerin; PINP, N-terminal propeptide of type I collagen; RANKL, receptor activator of the NFkappaB ligand.

Given that patients included in controlled trials are usually selected by strict inclusion criteria and therefore not fully representative of a real-life situation, some cohort studies were performed assessing the effect of anti-TNF on radiographic damage in subjects included in clinical registries. In these observational studies, the rate of radiographic progression in patients treated with TNF inhibitors was compared with that of subjects treated with other DMARDs, and a decreased radiographic progression after the initiation of anti-TNF treatment was a common finding. ${ }^{55-57}$

Recently, the first biosimilar anti-TNF inhibitor was approved by the EMA for the treatment of RA: CTP-13, a biosimilar infliximab, whose biosimilarity to innovator infliximab in the treatment of RA was demonstrated in a randomised, double-blind, prospective clinical trial. In the PLANETRA study, biosimilar infliximab showed an efficacy similar to that of innovator infliximab in obtaining an ACR20 response at 30 weeks in patients with RA concomitantly treated with MTX, with a comparable safety and immunogenicity profile. ${ }^{58}$

There are no published studies or trials registered at this moment exploring the effects of a biosimilar anti-TNF inhibitor on systemic and local bone loss in RA. Some data were presented during the EULAR 2104 congress on the effect of the infliximab biosimilar CTP-13 on radiographic progression in RA: in the extension of the PLANETRA study to a subgroup of patients with a follow-up of 54 weeks, the changes in radiographic scores from baseline were compared between biosimilar and innovator infliximab, and no significant differences were found in the total Sharp score (TSS), joint space narrowing score, and erosion score between the two drugs. ACR20 responders showed less TSS progression compared with non-responders in both treatment groups, but the differences were not statistically significant. $^{59}$

\section{CONCLUSIONS}

Despite extensive data on the biological action of TNF on bone, there is scarce evidence that TNF inhibition has a clinically meaningful effect on preventing fractures in patients with RA, and only data on surrogate markers of systemic bone loss are available. More consolidated data are available on the efficacy of anti-TNF therapy in limiting local bone loss and reducing radiographic progression related to the disease.

Contributors MM was involved in the study concept, writing of the manuscript, final approval of the version published, and agrees to be accountable for all aspects of the work in ensuring that questions related to the accuracy or integrity of any part of the work are appropriately investigated and resolved; LS was involved in the study concept, critical revision of the manuscript for important intellectual content, final approval of the version published, and agrees to be accountable for all aspects of the work in ensuring that questions related to the accuracy or integrity of any part of the work are appropriately investigated and resolved.

Competing interests None declared.

Provenance and peer review Commissioned; externally peer reviewed.

Data sharing statement No additional data are available.

Open Access This is an Open Access article distributed in accordance with the Creative Commons Attribution Non Commercial (CC BY-NC 4.0) license, which permits others to distribute, remix, adapt, build upon this work noncommercially, and license their derivative works on different terms, provided the original work is properly cited and the use is non-commercial. See: http:// creativecommons.org/licenses/by-nc/4.0/

\section{REFERENCES}

1. Lam J, Takeshita S, Barker JE, et al. TNF-alpha induces osteoclastogenesis by direct stimulation of macrophages exposed to permissive levels of RANK ligand. J Clin Invest 2000;106:1481-8.

2. Cenci S, Weitzmann MN, Roggia C, et al. Estrogen deficiency induces bone loss by enhancing T-cell production of TNF-alpha. $J$ Clin Invest 2000;106:1229-37.

3. Wei S, Kitaura H, Zhou P, et al. IL-1 mediates TNF-induced osteoclastogenesis. J Clin Invest 2005;115:282-90.

4. Osta B, Benedetti G, Miossec P. Classical and Paradoxical Effects of TNF-alpha on Bone Homeostasis. Front Immunol 2014;5:48.

5. Diarra D, Stolina M, Polzer K, et al. Dickkopf-1 is a master regulator of joint remodeling. Nat Med 2007;13:156-63. 
6. Harre U, Georgess D, Bang H, et al. Induction of osteoclastogenesis and bone loss by human autoantibodies against citrullinated vimentin. J Clin Invest 2012;122:1791-802.

7. Jimenez-Boj E, Nobauer-Huhmann I, Hanslik-Schnabel B, et al. Bone erosions and bone marrow edema as defined by magnetic resonance imaging reflect true bone marrow inflammation in rheumatoid arthritis. Arthritis Rheum 2007:56:1118-24.

8. McQueen FM, Benton N, Perry D, et al. Bone edema scored on magnetic resonance imaging scans of the dominant carpus at presentation predicts radiographic joint damage of the hands and feet six years later in patients with rheumatoid arthritis. Arthritis Rheum 2003;48:1814-27.

9. Schett G. Firestein GS. Mr Outside and Mr Inside: classic and alternative views on the pathogenesis of rheumatoid arthritis. Ann Rheum Dis 2010;69:787-9.

10. Sinigaglia L, Nervetti A, Mela Q, et al. A multicenter cross sectional study on bone mineral density in rheumatoid arthritis. Italian Study Group on Bone Mass in Rheumatoid Arthritis. J Rheumatol 2000;27:2582-9.

11. Haugeberg G, Lodder MC, Lems WF, et al. Hand cortical bone mass and its associations with radiographic joint damage and fractures in 50-70 year old female patients with rheumatoid arthritis: cross sectional Oslo-Truro-Amsterdam (OSTRA) collaborative study. Ann Rheum Dis 2004;63:1331-4.

12. Gravallese EM, Harada $Y$, Wang JT, et al. Identification of cell types responsible for bone resorption in rheumatoid arthritis and juvenile rheumatoid arthritis. Am J Pathol 1998;152:943-51.

13. Komine M, Kukita A, Kukita T, et al. Tumor necrosis factor-alpha cooperates with receptor activator of nuclear factor kappaB ligand in generation of osteoclasts in stromal cell-depleted rat bone marrow cell culture. Bone 2001;28:474-83.

14. Kotake S, Udagawa N, Hakoda M, et al. Activated human T cells directly induce osteoclastogenesis from human monocytes: possible role of $T$ cells in bone destruction in rheumatoid arthritis patients. Arthritis Rheum 2001;44:1003-12.

15. Bartok B, Firestein GS. Fibroblast-like synoviocytes: key effector cells in rheumatoid arthritis. Immunol Rev 2010;233:233-55.

16. Pettit $\mathrm{AR}$, Ji $\mathrm{H}$, von Stechow $\mathrm{D}$, et al. TRANCE/RANKL knockout mice are protected from bone erosion in a serum transfer model of arthritis. Am J Pathol 2001;159:1689-99.

17. Vis M, Havaardsholm EA, Haugeberg G, et al. Evaluation of bone mineral density, bone metabolism, osteoprotegerin and receptor activator of the NFkappaB ligand serum levels during treatment with infliximab in patients with rheumatoid arthritis. Ann Rheum Dis 2006:65:1495-9.

18. Seriolo B, Paolino S, Sulli A, et al. Bone metabolism changes during anti-TNF-alpha therapy in patients with active rheumatoid arthritis. Ann N Y Acad Sci 2006;1069:420-7.

19. Marotte H, Pallot-Prades B, Grange L, et al. A 1-year case-control study in patients with rheumatoid arthritis indicates prevention of loss of bone mineral density in both responders and nonresponders to infliximab. Arthritis Res Ther 2007;9:R61.

20. Chopin F, Garnero P, le Henanff A, et al. Long-term effects of infliximab on bone and cartilage turnover markers in patients with rheumatoid arthritis. Ann Rheum Dis 2008:67:353-7.

21. Guler-Yuksel M, Bijsterbosch J, Goekoop-Ruiterman YP, et al. Changes in bone mineral density in patients with recent onset, active rheumatoid arthritis. Ann Rheum Dis 2008:67:823-8.

22. Lange U, Teichmann J, Muller-Ladner U, et al. Increase in bone mineral density of patients with rheumatoid arthritis treated with anti-TNF-alpha antibody: a prospective open-label pilot study. Rheumatology 2005;44:1546-8.

23. Krieckaert CL, Nurmohamed MT, Wolbink G, et al. Changes in bone mineral density during long-term treatment with adalimumab in patients with rheumatoid arthritis: a cohort study. Rheumatology 2013:52:547-53

24. Vis M, Voskuyl AE, Wolbink GJ, et al. Bone mineral density in patients with rheumatoid arthritis treated with infliximab. Ann Rheum Dis 2005;64:336-7.

25. Haugeberg G, Conaghan PG, Quinn M, et al. Bone loss in patients with active early rheumatoid arthritis: infliximab and methotrexate compared with methotrexate treatment alone. Explorative analysis from a 12-month randomised, double-blind, placebo-controlled study. Ann Rheum Dis 2009;68:1898-901.

26. Wijbrandts CA, Klaasen R, Dijkgraaf MG, et al. Bone mineral density in rheumatoid arthritis patients 1 year after adalimumab therapy: arrest of bone loss. Ann Rheum Dis 2009;68:373-6.

27. Eekman DA, Vis M, Bultink IE, et al. Stable bone mineral density in lumbar spine and hip in contrast to bone loss in the hands during long-term treatment with infliximab in patients with rheumatoid arthritis. Ann Rheum Dis 2011;70:389-90.
28. Dischereit G, Tarner IH, Muller-Ladner $\mathrm{U}$, et al. Infliximab improves bone metabolism and bone mineral density in rheumatoid arthritis and ankylosing spondylitis: a prospective 2-year study. Clin Rheumatol 2013;32:377-81.

29. Okano T, Koike T, Tada M, et al. The limited effects of anti-tumor necrosis factor blockade on bone health in patients with rheumatoid arthritis under the use of glucocorticoid. J Bone Miner Metab 2014;32:593-600.

30. Szentpetery A, McKenna MJ, Murray BF, et al. Periarticular bone gain at proximal interphalangeal joints and changes in bone turnover markers in response to tumor necrosis factor inhibitors in rheumatoid and psoriatic arthritis. J Rheumatol 2013;40:653-62.

31. Haugeberg G, Strand A, Kvien TK, et al. Reduced loss of hand bone density with prednisolone in early rheumatoid arthritis: results from a randomized placebo-controlled trial. Arch Intern Med 2005;165:1293-7.

32. Engvall IL, Svensson B, Tengstrand B, et al. Better Anti-Rheumatic FarmacO Therapy Study Group. Impact of low-dose prednisolone on bone synthesis and resorption in early rheumatoid arthritis: experiences from a two-year randomized study. Arthritis Res Ther 2008;10:R128.

33. Vis M, Wolbink GJ, Lodder MC, et al. Early changes in bone metabolism in rheumatoid arthritis patients treated with infliximab. Arthritis Rheum 2003;48:2996-7.

34. Ziolkowska M, Kurowska M, Radzikowska A, et al. High levels of osteoprotegerin and soluble receptor activator of nuclear factor kappa B ligand in serum of rheumatoid arthritis patients and their normalization after anti-tumor necrosis factor alpha treatment. Arthritis Rheum 2002:46:1744-53.

35. Torikai E, Kageyama $\mathrm{Y}$, Takahashi $\mathrm{M}$, et al. The effect of infliximab on bone metabolism markers in patients with rheumatoid arthritis. Rheumatology 2006;45:761-4.

36. Yasunori K, Masaaki T, Tetsuyuki N, et al. Reduction of urinary levels of pyridinoline and deoxypyridinoline and serum levels of soluble receptor activator of NF-kappaB ligand by etanercept in patients with rheumatoid arthritis. Clin Rheumatol 2008;27:1093-101.

37. Korczowska I, Lacki JK, Hrycaj P. Influence of infliximab on cytokines network and markers of bone remodeling in rheumatoid arthritis patients. Yonsei Med J 2013;54:183-8.

38. Lim MJ, Kwon SR, Joo K, et al. Early effects of tumor necrosis facto inhibition on bone homeostasis after soluble tumor necrosis factor receptor use. Korean J Intern Med 2014;29:807-13.

39. Choi BY, Chang SH, Cho HJ, et al. The association of radiographic progression with serum R-spondin 1 (RSPO1) levels or Dickkopf-1 (DKK1)/RSPO1 ratios in rheumatoid arthritis patients: clinical evidence for reciprocal inhibition between DKK1 and RSPO1. Scand $J$ Rheumatol 2014:43:453-61.

40. Kawai VK, Grijalva CG, Arbogast PG, et al. Initiation of tumor necrosis factor alpha antagonists and risk of fractures in patients with selected rheumatic and autoimmune diseases. Arthritis Care Res (Hoboken) 2013;65:1085-94.

41. Kim SY, Schneeweiss S, Liu J, et al. Effects of disease-modifying antirheumatic drugs on nonvertebral fracture risk in rheumatoid arthritis: a population-based cohort study. J Bone Miner Res 2012;27:789-96.

42. Roussy JP, Bessette L, Bernatsky S, et al. Rates of non-vertebral osteoporotic fractures in rheumatoid arthritis and postfracture osteoporosis care in a period of evolving clinical practice guidelines. Calcif Tissue Int 2014;95:8-18.

43. Hoff M, Kvien TK, Kalvesten J, et al. Adalimumab therapy reduces hand bone loss in early rheumatoid arthritis: explorative analyses from the PREMIER study. Ann Rheum Dis 2009;68: 1171-6.

44. Hoff M, Kvien TK, Kalvesten J, et al. Adalimumab reduces hand bone loss in rheumatoid arthritis independent of clinical response: subanalysis of the PREMIER study. BMC Musculoskelet Disord 2011;12:54.

45. Bertoldi I, Filippou G, Scire CA, et al. Disease activity and bone mineral density of MCP joints in patients with rheumatoid and psoriatic arthritis: is there a correlation?-A study in patients treated with methotrexate and an anti-TNF alpha agent. ISRN Rheumatology 2013;2013:708323.

46. Genovese MC, Bathon JM, Martin RW, et al. Etanercept versus methotrexate in patients with early rheumatoid arthritis: two-year radiographic and clinical outcomes. Arthritis Rheum 2002:46:1443-50.

47. Breedveld FC, Weisman MH, Kavanaugh AF, et al. The PREMIER study: a multicenter, randomized, double-blind clinical trial of combination therapy with adalimumab plus methotrexate versus methotrexate alone or adalimumab alone in patients with early, 
aggressive rheumatoid arthritis who had not had previous methotrexate treatment. Arthritis Rheum 2006;54:26-37.

48. St Clair EW, van der Heijde DM, Smolen JS, et al. Combination of infliximab and methotrexate therapy for early rheumatoid arthritis: a randomized, controlled trial. Arthritis Rheum 2004;50:3432-43.

49. Emery P, Fleischmann R, van der Heijde D, et al. The effects of golimumab on radiographic progression in rheumatoid arthritis: results of randomized controlled studies of golimumab before methotrexate therapy and golimumab after methotrexate therapy. Arthritis Rheum 2011;63:1200-10.

50. Lipsky PE, van der Heijde DM, St Clair EW, et al. Infliximab and methotrexate in the treatment of rheumatoid arthritis. Anti-Tumor Necrosis Factor Trial in Rheumatoid Arthritis with Concomitant Therapy Study Group. N Engl J Med 2000;343:1594-602.

51. Klareskog $L$, van der Heijde D, de Jager JP, et al. Therapeutic effect of the combination of etanercept and methotrexate compared with each treatment alone in patients with rheumatoid arthritis: double-blind randomised controlled trial. Lancet 2004;363:675-81.

52. Keystone EC, Kavanaugh AF, Sharp JT, et al. Radiographic, clinical, and functional outcomes of treatment with adalimumab (a human anti-tumor necrosis factor monoclonal antibody) in patients with active rheumatoid arthritis receiving concomitant methotrexate therapy: a randomized, placebo-controlled, 52-week trial. Arthritis Rheum 2004;50:1400-11.

53. Keystone E, Heijde D, Mason D Jr, et al. Certolizumab pegol plus methotrexate is significantly more effective than placebo plus methotrexate in active rheumatoid arthritis: findings of a fifty-two-week, phase III, multicenter, randomized, double-blind, placebo-controlled, parallel-group study. Arthritis Rheum 2008;58:3319-29.

54. Favalli EG, Pregnolato $\mathrm{F}$, Biggioggero $\mathrm{M}$, et al. The role of biologic agents in damage progression in rheumatoid arthritis: indirect comparison of data coming from randomized clinical trials. Ther Adv Musculoskelet Dis 2012;4:213-23.

55. Ornbjerg LM, Ostergaard M, Boyesen $\mathrm{P}$, et al. Impact of tumour necrosis factor inhibitor treatment on radiographic progression in rheumatoid arthritis patients in clinical practice: results from the nationwide Danish DANBIO registry. Ann Rheum Dis 2013;72:57-63.

56. Pavelka K, Gatterova J, Tegzova D, et al. Radiographic progression of rheumatoid arthritis in patients from the Czech National Registry receiving infliximab treatment. Clin Exp Rheumatol 2007;25: 540-5.

57. Finckh A, Simard JF, Duryea J, et al. The effectiveness of anti-tumor necrosis factor therapy in preventing progressive radiographic joint damage in rheumatoid arthritis: a population-based study. Arthritis Rheum 2006;54:54-9.

58. Yoo DH, Hrycaj $\mathrm{P}$, Miranda $\mathrm{P}$, et al. A randomised, double-blind, parallel-group study to demonstrate equivalence in efficacy and safety of CT-P13 compared with innovator infliximab when coadministered with methotrexate in patients with active rheumatoid arthritis: the PLANETRA study. Ann Rheum Dis 2013;72:1613-20.

59. Yoo DH, Park W, Miranda $P$, et al. Inhibition of radiographic progression and its association with clinical parameters in RA patients treated with CT-P13 and innovator Infliximab in PLANETRA study. Ann Rheum Dis 2014;73(Suppl 2):234-5. 